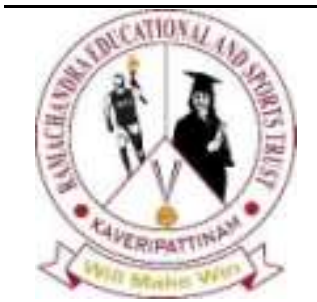

REST Journal on Emerging trends in Modelling andManufacturing

Vol: 7(3), 2021

REST Publisher

ISSN: 2455-4537

Website: www.restpublisher.com/journals/jemm

\title{
A Review on Biodiesel Properties and Fatty acid composites
}

P. K. Chidambaram, Dr. Amol Lokhande, Dr. M. Ramachandran, Vimala Saravanan, Vidhya Prasanth

New Prince shri bhavani college of Engg. \& Tech Chennai, Tamil Nadu, India.

School of Engineering and Technology, Sandip University. Maharashtra, India.

REST LABS, Kaveripattinam, Krishnagiri, Tamil Nadu, India.

Email: hodmech@newprinceshribhavani.com

\begin{abstract}
Biodiesel is a vegetable oil, Animal fat or recycled grease is a locally produced renewable, biodegradable material Is the fuel. ... Renewable diesel, also known as "green diesel" different from biodiesel. Biodiesel is a liquid fuel, mostly P100 or pure biodiesel Indicates in its pure, unadulterated form. The problem is that we cannot even produce oil for the needs of our own citizens. We have been importing oil from other countries to meet the demand. Under such circumstances biodiesel could not be produced from cooking oils like other countries. Biodiesel Petroleum is a locally made, clean, combustible, renewable alternative to Diesel. Using biodiesel as a vehicle fuel improves energy saving, air quality and the environment Provides security. Biodiesel Petroleum Diesel cleans combustible domestically. Is a renewable alternative. Using biodiesel as a vehicle fuel is energy Improves storage and air quality and improves the environment and safety benefits Provides. Biodiesel transesterification is made from oils or fats and is very common in Europe. In its pure form (B100) it is used as a fuel for vehicles Used, but also from particles, carbon monoxide and diesel-powered vehicles. It is commonly used as diesel Addition that reduces the amount of hydrocarbons. Biodiesel is Petroleum is direct replacement for diesel and can be used in any diesel engine without any modification. ... Up to $75 \%$ of the total emissions from using biodiesel in a diesel engine can be reduced. Diesel vehicle engine wear and excess lubrication will naturally last longer. Audi, BMW, Porsche and Volkswagen are all diesel Offer models, and all can use biodiesel blends. Most in the United States Biodiesel fuels are made from soybean oil. Yes, in biodiesel, it is may be true. As an alternative fuel, such as gasoline and fossil fuels, biodiesel is a precursor to biofuels made from renewable fuels based on animal or vegetable fat. Also, used cooking oil (UCO) can be used effectively to produce bibfuls and is of great use in diesel vehicles.
\end{abstract}

\section{Introduction}

Biodiesel has higher oxygen content (typically 10 to 12 percent) than petroleum diesel. ... Biodiesel is more chemically active as a solvent than petroleum diesel. As consequence, diesel in general this Can be very aggressive to some products that are considered fuel safe. Biodiesel is much cheaper than petroleum diesel toxicity. Befouls is a renewable alternative to fossil fuels, mainly corn, soybeans, wheat and sugarcane. From such crop plants is produced. But with animal fats and other by-products, household food waste together, they can be used to make pitfalls. Yes, you can use biodiesel and diesel fuel as an alternative, as well as a mixed problem is that we cannot even produce oil. The needs of our own citizen. We have been importing oil from other countries to meet the demand. Under such circumstances biodiesel could not be produced from cooking oils like other countries. Biodiesel and conventional diesel vehicles are one and the same. Lightweight, Medium and Heavy Diesel Vehicles Technology although not fundamentally alternative fuel vehicles, almost all are capable of running on biodiesel blend with. B20 and down line alloys are used without engine in many diesel vehicles replacement cannot. One of the biggest problems biodiesel manufacturers have recently encountered has nothing to do with the conversion process - it is diesel related to engines. Is. Until two years ago, all diesel engines were B100compliant (could not run on biodiesel petrol engines because it requires a compression welding machine). Vehicles running without petrol and diesel are known as green vehicles or alternative fuel vehicles. Vehicles running without petrol or diesel include electric cars, electric bicycles and rickshaws. Can my car use befoul? You cannot fill your car with pure bio ethanol or biodiesel, but with a low percentage of compatibility issues your car will run properly on unadulterated unleaded and diesel. If you are trying to convert a standard petrol vehicle to biodiesel, you must first replace the entire motor running on diesel. This is not an economical process, and most people prefer to switch to biodiesel for economic or environmental reasons, or both.

\section{Biodiesel Properties}

[65] The oxidation process of biodiesel involves three basic steps: initiation, diffusion and termination. First, from carbon acids and hydrogen polyunsaturated fat is eliminated. Base radical (R :), which produces proxy active (ROO :) and hydro peroxide $(\mathrm{ROOH})$. Will do. This peroxide forms a new radical in the esters that binds with the oxygen in the air. No Over time, the amount of hydro peroxide spreads rapidly. It is automated in the oxidation phase, where the formation of decomposition by-products occurs at a high rate. [59] During data collection, exclude duplicate entries and measure actual 
reported values in accordance with internationally accepted test standards. Specific attempts were made to include only the data of the researchers. Although the initial purpose is to add up the entire If Property values are found, and some significant 'excess' data eventually exclusion from the database is inevitable. For example, the density for a particular FAME is 860 to $880 \mathrm{~kg} / \mathrm{m} 3$ the researchers also found that the value excluded from the specific researcher database was 840 or $910 \mathrm{~kg} / \mathrm{m} 3$. . However, more than one different researcher is serious about such if the values are confirmed, they will be retained in the database and eventually retrieved. Will be reflected at the Corresponding high values of standard deviations. Also, it is primarily density and viscosity Is valid, although some researchers have used data for these two properties at 15 and $40 \mathrm{C}$, respectively The global demand for is not provided by temperature.; [53] On the other hand, the area where the cold filter meets the threshold of the plugging point parameter has the lowest saturated resin esters at the saturation angle point (blue area). An All biodiesel except palm belongs for this region. Peanut biodiesel is not considered for this classification because, as mentioned above, peanut CFPP Did not meets the specification because the long carbon chain is the length of the methyl ester and the carbon chain Is triangular. Not included. Of all the biodiesel in this area The monosaturated ester content was in the range of 20-80 wt. \% [45] On the other hand, the area where the cold filter meets the threshold of the plugging point parameter is the lowest at the saturation angle (blue area). Contains saturated resin Esters. All biodiesel except palm belongs to the region. Peanut biodiesel for this classification not considered, because, as mentioned above, seafood is CFPP due to its long carbon content Profile not completed. The chain is saturated with Length of methyl ester and Carbon chain triangle. Not included. All of the biodiesel in this area, The content of monounsaturated methyl ester was in the range of 20-80 wt. \% [9] the most important step of the PNPB is Act No. dated January 13, 2005. Is 13. 11097 Introduces fuels derived from the oils and fats in the Brazilian Energy Matrix. ; After that year, B2 Will be mandatory. Between 2008 and 2013, 5\% biodiesel compounds may be used, and B5 is mandatory for this period. [33] Fat esters, compounds, contaminants And those with smaller components, dictate the Fuel properties of biodiesel fuel. Because each ingredient has a unique chemical composition, it differs in nutrients; the biodiesel produced has different Fuel properties. Temperature of low fat ester compound and biodiesel core, impurities and small components Functionality, antioxidant and storage stability, kinetic viscosity, emissions, granite number and energy Properties that are directly affected by the content. In the context of biodiesel, small components are defined as naturally occurring species

\section{Fatty acid composites}

[68] In this review, the lubricity was rated at 25 and 60 C ASTM uses the D-6079 method, which predicts the validity of the reported package data. Various compounds have been elegantly studied compounds containing fuels or petro diesel. Table 2 Fuel Specification Depreciation Value (ULSD, DF1, biodiesel). Effect of lubrication on explicit ULSD. Commercial biodiesel, by far, has the best lubricity of reference fuel. For this behavior of biodiesel The reasons are discussed below. Petro Diesel Table 3 lists the results of hydrocarbons, some of which are relatively bonded to fuel. In biodiesel Table 4 fuel Provides values for found pure fat compounds. The HFRR data of compounds containing $10 \mathrm{C}$ atoms (C10) are shown in Table 5. 3. C atoms Table 6 (C3) and HFRR data compounds of the OH, NH2 and SH groups. HFRR Data for Included Petro Diesel Fuels Table 7 (Lubricant Given in ULSD Fuel) and Table 8 (Low Lubricity No. 1 Diesel Fuel). [66] "Biodiesel" is a long chain fat derived from fats Mono-alkyl esters containing vegetable oils or animal oils oils labeled "B100" Refers to fuel. European specification as a fatty acid ester (FAME) fuel Refers to fuel. European specification as a fatty acid ester (FAME) fuel with biodiesel standard EN 14214. Transliteration reaction. It can be argued that "bio" is when methanol is produced as a component of approximately $95 \%$ of the carbon atoms in biodiesel. The reason is that although methanol is derived from renewable resources, it is generally non-renewable natural No judgment has been given as to what is derived from the gas. To calculate the average aggregate result (wt. \%) For each species all values are initially accepted as equal were weighed. For an individual species, the distribution of reported values (from a given feed) is then analyzed and averaged Is found to be Far from the values (usually> 2 standard deviations). The original is the literary source of these "exteriors" By reviewing and correcting data input errors Were first explored. In some cases, the errors are obvious though not were found, the exteriors were removed when calculating algorithms and standard deviations. [58] 1,488 / 5,000Translation results . Twelve types Test models of fatty acid methyl esters were tested These include: Biodiesel differs in C14: 0, C16: 0, C16: 1, C18: 0, C18: 1, C18: 2, C18: 3, C20: 0, C20: 1, C22: 0, C22: 1 and C24: 0 HP 6890 equipped with acids 3365 / IIGC The composition of the series II gas chromatograph esters was determined. By a flame ionization station and detection. Capillary program HP-INNO wax (cross-linked) PEG) column 30 $\mathrm{m}$ long, $0.5 \mathrm{~lm}$ image thickness and $0.32 \mathrm{~mm}$ ID. The split ratio is $45: 1$. The oven temperature is $150 \mathrm{C}$ for $1 \mathrm{minute}$ and then $225 \mathrm{C}$ for $15 \mathrm{C} /$. If heated for 5 minutes, it is $5 \mathrm{C} /$. Heats up to $260 \mathrm{C}$ per minute. For 7 minutes. Helium was used as a carrier gas and auxiliary gas for FID with a flow rate of $2.1 \mathrm{ml} / \mathrm{min}$. [22] obvious problems include during storage and combustion formation including High viscosity, acid composition, free fatty acid content, as well as carbon deposition and lubrication Adhesion due to oxidation and polymerization. Heating and mixing vegetable oils can reduce viscosity and vegetable oils can improve instability but because it's molecular structure remains the same. Polyunsaturated. Plant in diesel engines to use oils, significant mechanical changes in piping structure are required, including replacement of injector construction materials. machine will run Time will decrease; excessive wear will increase maintenance costs and increase the risk of mechanical failure. [17] The most common way to produce biodiesel is in this reaction, the main constituents of vegetable oils being triglycerides, esters with alcohol React. Forms fatty acids called glycerol. Very high compared to other alcohols the most common alcohol available at low prices is methanol. In this case, the reaction is referred to as methanol $3 \mathrm{~mol}$ and $1 \mathrm{~mol}$ triglyceride and $3 \mathrm{~mol}$. mol fat, the acid being methyl ester and 1 mol should be 
given by glycerol. This reaction involves triglycerides and three consecutive reactive reactions mono $*$-related teacher intermediates. [11] In this review, no preconceived notions were given about the validity of the reported data set. At the beginning of all the values to calculate the average compound result (wt. \%) For each species were accepted and weighed equally. The after the distribution of the reported values (from a given feed) for an individual species was examined and identified as far removed from the mean values (usually> 2 standard deviations). These are "externalities" are also data input by first reviewing the original literature source Errors were also investigated by correcting. Some in some cases, obvious errors although not found, the exteriors were removed when calculating algorithms and standard deviations.

\section{Waste Cooking oil (WCO)}

[57] As mentioned, the temperature varies from 25 to 65 degrees Celsius. For the same final reaction time, the percentage of esters increased with temperature. After $5 \mathrm{~min}$, the esters at 65, 45 and $25 \mathrm{C}$ were 84.7, 61.6 and, respectively Showing 49.3\%. Shows the effect of temperature on change. In 120 minutes, the percentages were 94.2 and 79.9, respectively And 69.8. So, there was an initial period in which the reaction was very fast, followed by a second period, Longer than the first period, in which the mixture slowly formed towards equilibrium. [51] To get for optimal yields, these algae should contain high levels of carbon dioxide (CO2) In Binary molecules produce electricity that produces an average of $13 \% \mathrm{CO} 2$ in total exhaust emissions. Connected to conventional thermal power plants to. $\mathrm{CO} 2$ is stored in basins and synthesized by algae. This is the water used is a technology that recycles $\mathrm{CO} 2$ during refining. [16] Helianthus annulus Botanical name given to sunflower, which Is a member of a mix of flowering plants from around the world. The name is derived from the word halos, which is a Greek word meaning sun And the anthem derived from the flower. Southwestern America and parts of sunflower Mexico appeared, There sunflower is mostly cultivated for decoration and sometimes for consumption. Sunflower The seeds are edible and often crushed to extract the oil. Sunflower oil contains essential oleic and linoleum fatty acids found in sunflower considered one of the oldest oils. Seeds because its cultivation dates back to $3000 \mathrm{BC}$. Before the soybean boom after World War II, there was sunflower once the world's leading oil producer. [64] The excitation acceleration limit reaches $16 \mathrm{mg}$ and its sensitivity (resolution) decreases below $4 \mathrm{mg}$, while the acceleration level of the strong stimulus Much less than the building reaction (50-300 mg). Ambient vibration, on the other hand The system is insensitive to acceleration $(0.1-0.3 \mathrm{mg})$. The typical response of the building is $20 \mathrm{~Hz}$ [36, 48-53] Many authors state that. Also, a system with a base frequency of more than $10 \mathrm{~Hz}$ Characterized by very high rigidity. In the above facts basically, the internal accelerometer lacks analog anti-conversion filtration and most of the building's vibration and / or vibration energy are in the $0-10 \mathrm{~Hz}$ frequency range. $40 \mathrm{~Hz}$ sample rate selected, [39] Fodder for biodiesel can be divided into oilseeds, soybeans, rapeseed and more; Oil trees including Chinese pistachio and palm oil; And other animal fats, waste oil diet. Due to its excellent environmental and renewable properties, The fatty acid methyl ester (FAME) is particularly important. One of the advantages of this fuel is that it is manufactured; Essentials Can be used naturally and renewably. All of these oils are vegetable or animal Made from fats, they are biodegradable and non-toxic. The general chemical properties of vegetable oils are given in Table 2, while fats in different vegetable oils the common components of acids are given in Table 3. It is Cool Transfer to extraction funnel after room temperature. The catalyst is divided into Solid form in the reaction vessel. Following the separation of the layers of ester and glycerin, methanol in the ester phase in a rotary evaporator under vacuum Removed. The ester phase is taken back to the separating funnel. Petroleum ether (equivalent to ester phase) and distilled water $(20 \mathrm{C}$ and double ester After the addition of volume (volume), the $\mathrm{pH}$ of the solution was adjusted to 7 by the addition of acetic acid. The rinsing process is repeated three times in distilled water. [32] The following sections emphasize the modern review of current biodiesel processing technologies in the form of Enzyme modification. Biodiesel enzyme activity, current technological challenges and future development opportunities Detailed analysis of the latest biotechnology developments in, enzymes in light It aims to reduce costs and improve the overall process economy towards large-scale enzyme biodiesel production.

\section{Transesterification}

[56] As mentioned above, basic catalysis is the general process of converting an oil or fat into biodiesel with alcohol (metamorphic reaction). See Figure 1 for policy). Bases such as Noah or $\mathrm{KOH}$ are commonly used, although alkaloids such as $\mathrm{NaOCH} 3$ react with $\mathrm{XOH}$. Please respond. Do they benefit from doing water? in the base-catalyzed transesterification must be kept to a minimum [38] Retail Trisperma oil in this process is pre-fitted with a condenser and an overhead stirrer. The heated double-jacket is poured into a glass furnace. Next, the minutes. Upon completion of the transesterification process, the reaction compound is transferred from glycerol to a separation funnel separating rutalis trisperma methyl ester. Left stand. [2] 10 than petroleum diesel fuel the first is 17 times higher. Very viscous with viscosity. Biodiesel is made by converting fat to achieve close viscosity to Thai oil or petro diesel. Transesterification is the process of converting oil into a fatty ester (biodiesel) associated with it 1-4 carbon atoms are: [24] Glycerol is removed as a by-product. The esters produced are called biodiesel. According to ASTM D6751, standard biodiesel is at least 96.4\% Must contain esters. The rest are water, sediment, free glycerol, methanol, triglyceride, triglyceride, alkaline metals and alkaline earth metals). The presence of these components in the fuel can greatly affect the properties. According to the standard, the range of these contaminants and the desired fuel properties are given in Table 1 Are given. Many properties of biodiesel may deviate from the standard once biodiesel is decomposed, even if it meets the given standard when obtained. Therefore, the composition of biodiesel and it is important to systematically examine the factors that can because 
instability based on the fuel properties associated with it. [29] As a result of these problems, these vegetable oils have become an appropriate and viable biodiesel fuel Attempts have been made to change that. Mango and Hannah are three well established for biodiesel production Methods reviewed, i.e. micro-emulsion, thermal cracking and transsterisification. Deepening is so popular and desirable that its preference is clearly stated in detail. [14] Peanut oil was demonstrated as a fuel at the Paris World's Fair. Government of affordable price, high availability and petroleum derived diesel their use continued until the 1920s, before the complete elimination of vegetable oils from the market due to subsidies. This led manufacturers to replace diesel engine with diesel derived from low-viscosity petroleum, making the use of vegetable oils no longer possible. In the 1970s, the lack of fossil fuel supply and safety caused vegetable oils Sparked interest in developing alternative energy. [20] Membrane equipment often used to separate and purify crude biodiesel, such as eliminating / reducing high capital costs and other associated production costs have many benefits. Membrane equipment for biodiesel treatment is usually made from mineral microporous ceramic membranes. Many applications are made in biotechnology in general. These membranes are twofold Are divided, which depends to some extent on the application. Used to separate and purify crude biodiesel some of the most effective devices are: membrane furnace and ceramic membrane separator.

\section{Ethanol}

[61] The mixing of bio-ethanol with diesel fuel is an option in contrast to consolidating sustainable power into auto fuel, which is acquiring developing consideration for its monetary and natural advantages. Some It is normal practice in Europe to join biodiesel content into business diesel fuel and increment interest in ethanol mixes because of the inescapable consistency when biodiesel is added. In any case, one of the fundamental worries is related with ethanol grease misfortune. The mix of biodiesel with biodiesel has additionally been accounted for in the writing. These mixtures differ as indicated by actual steadiness and ASTM principles Tested for fuel properties. Execution and emanation trial of every motor were directed at the same time. Perceptions, compounds are heat and actually steady, and they show great likeness with the properties of diesel aside from the blaze point. [39] Biodiesel Petroleum-Fuel As a promising option in contrast to nonrenewable energy sources for diesel motors, the ecological effect of diesel motors and declining oil assets are progressively significant. Ethanol methanol or Naturals, for example, biodiesel, can be artificially mixed with oil or fat to frame liquor. Methanol is the most regularly involved liquor in the business creation of biodiesel. Biodiesel is produced using vegetable oil and diesel numerous examinations have shown that it very well may be utilized appropriately in motors. Indeed, the energy thickness of biodiesel is extremely near that of customary diesel. There is. Soybeans within the sight of corrosive impetuses and Biodiesel can be delivered from methanol. The similitude's between the burning properties of biodiesel and petrol inferred diesel make the previous the most encouraging inexhaustible and supportable fuel. Vehicles. [37] Transesterification is the method involved with transforming one ester from another, for example, glycerol esters, which make up vegetable oils and alkyl which make up biodiesel. Is the substance interaction of changing over ester? This is finished by responding liquor with vegetable oil within the sight of a basic or corrosive impetus. The cycle happens. For example, ethanol, methanol or butane Alcohol can be utilized in transesterification, and these liquor esters are methyl esters, individually. Named as ethyl esters or butyl esters. Tung state is the strong corrosive impetus for the hydroxide, sodium meth oxide and potassium hydroxide antacid impetuses [25] Zirconium-Alumina (WZA), sulfated zirconiumalumina (SZA), sulfated tin-oxide (15) fluorine) and $\mathrm{TiO} 2 / \mathrm{ZrO} 2, \mathrm{Al} 2 \mathrm{O} 3 / \mathrm{ZrO} 2$, ferric sulfate and $\mathrm{ZO}$ metals. Methanol with n-maritime corrosive in WZA, SZA, STO, TiO2/ZrO2, and Al2O3/ZrO2 and methanol in 175-200 8C with soybean oil in 200-300 8C is supplanted by methanol. More on tungsten zircon-alumina (WZA) etherification and transesterification responses Provides adjustment and is fit for enduring somewhat high temperatures (250 8C). [14] The unsaturated fat biodiesel, otherwise called methyl ester (FAME), is generally added to methanol in vegetable oil or in creature structure. Is likewise made by changing over fats, and the oil fluid has comparative synthesis and properties contrasted with those acquired. Diesel, for example, energy content, thickness and stage changes. Consequently, when blended in with diesel got from petrol, any CI diesel with practically no change it can likewise Used in machines. Low ozone depleting substance discharges, high lubricity and numerous remarkable benefits over diesel got from oil have made biodiesel the most well-known befoul on the planet. [4] Adult gas (CNG), lique3ed petroleum gas (LNG), lique3ed propane gas (LPG), methanol (M85 or M100), ethanol (E85 or E100), power and hydrogen (normally an energy component vehicle). This none of the energizes are appropriate for use in diesel motors. Nonetheless, it is available sudden spikes in demand for that elective fuel the complete number of vehicles on the streets of the United States is 330,000, which is more than 1.5 million around the world. [13] The creation of triacetate is of extraordinary Curiosity, since methanol it very well may be gotten by supplanting it with methyl acetic acid derivation. Additionally, triacetin rather than unsaturated fats containing acidic corrosive atoms is viewed as a low sub-atomic weight fatty oil. Diesel It is a verifiable truth that vegetable oils (fatty oils) can be utilized in motors. In any case, High thickness of fatty oils prompts the issue (albeit the active consistency at $40 \mathrm{C}$ is 35-40,the consistency Fatty acids are near methyl esters, thus the properties of biodiesel mixtures ought to be investigated as they can be utilized in biodiesel compounds.

\section{Conclusion}

During data collection, particular efforts were made to exclude only copy data from researchers who have duplicated inputs and internationally accepted test standards and actually measured reported values. All property values found although the initial purpose was to add, It was inevitable that some significant 'excess' data would eventually be excluded from the database. For example, a specific FAME For most researchers, the density can range from 860 to $880 \mathrm{~kg} / \mathrm{m} 3 \mathrm{and}$ 
a specific researcher value of 840 or $910 \mathrm{~kg} / \mathrm{m} 3$ can be estimated. If reported, this value will be excluded from the database. . However, researchers say there are more than 2 differences If confirmed, such extreme values will be retained in the database and reflected at correspondingly higher values of the standard deviations. Eventually obtained. The effect of lubrication on the ULSD is obvious. Bonded to the fuel. Found in biodiesel fuel Purity gives the values for Table 4 fat compounds. Table 5 shows HFRR data of compounds containing $10 \mathrm{C}$ atoms (C10). Table $63 \mathrm{C}$ atoms (C3) and HFRR data $\mathrm{OH}, \mathrm{NH} 2$ and shows combinations of SH groups. Sun from the Greek word halos, and flower the name is also derived from the meaning of the anthem. Sunflower appeared in parts of southwestern America and Mexico, and sunflower is often cultivated for decoration and before the soybean boom after World War II leading oil was the manufacturer. Next, the 150 minutes. Upon completion of the transesterification process, the reaction compound is a separation funnel and diesel Converted to fossil fuel for engines. As a promising alternative, rutalis trisperma methyl ester was left to stand apart by glycerol. Biodiesel. Petroleum fuel Diesel engines and declining petroleum resources. Natural oils or methanol or ethanol such fats can be mixed with alcohol to make biodiesel. Methanol in the commercial production of biodiesel Is the most commonly used alcohol. Many studies on biodiesel are made from vegetable oil Show that fuels can be used properly in diesel engines; in fact the energy density of biodiesel is very close to that of conventional diesel.

\section{Reference}

1. Sorate, Kamalesh A., and Purnanand V. Bhale. "Biodiesel properties and automotive system compatibility issues." Renewable and Sustainable Energy Reviews 41 (2015): 777-798.

2. Giakoumis, Evangelos G. "A statistical investigation of biodiesel physical and chemical properties, and their correlation with the degree of unsaturation." Renewable Energy 50 (2013): 858-878.

3. Ramos, María Jesús, Carmen María Fernández, Abraham Casas, Lourdes Rodríguez, and Ángel Pérez. "Influence of fatty acid composition of raw materials on biodiesel properties." Bioresource technology 100, no. 1 (2009): 261-268.

4. Bhale, Purnanand Vishwanathrao, Nishikant V. Deshpande, and Shashikant B. Thombre. "Improving the low temperature properties of biodiesel fuel." Renewable energy 34, no. 3 (2009): 794-800.

5. Barabás, István, and Ioan-Adrian Todoruţ. "Biodiesel quality, standards and properties." Biodiesel-quality, emissions and by-products (2011): 3-28.

6. Pousa, Gabriella PAG, André LF Santos, and Paulo AZ Suarez. "History and policy of biodiesel in Brazil." Energy Policy 35, no. 11 (2007): 5393-5398.

7. Moser, Bryan R. "Biodiesel production, properties, and feedstocks." Biofuels (2011): 285-347.

8. Knothe, Gerhard, and Kevin R. Steidley. "Lubricity of components of biodiesel and petrodiesel. The origin of biodiesel lubricity." Energy \& fuels 19, no. 3 (2005): 1192-1200.

9. Knothe, Gerhard. "Biodiesel and renewable diesel: a comparison." Progress in energy and combustion science 36, no. 3 (2010): 364-373.

10. Refaat, A. A. "Correlation between the chemical structure of biodiesel and its physical properties." International Journal of Environmental Science \& Technology 6, no. 4 (2009): 677-694.

11. Leung, D. Y. C., B. C. P. Koo, and Y. Guo. "Degradation of biodiesel under different storage conditions." Bioresource technology 97, no. 2 (2006): 250-256.

12. Abbaszaadeh, Ahmad, Barat Ghobadian, Mohammad Reza Omidkhah, and Gholamhassan Najafi. "Current biodiesel production technologies: A comparative review." Energy Conversion and Management 63 (2012): 138148.

13. Berrios, M., and R. L. Skelton. "Comparison of purification methods for biodiesel." Chemical Engineering Journal 144, no. 3 (2008): 459-465.

14. Hoekman, S. Kent, Amber Broch, Curtis Robbins, Eric Ceniceros, and Mani Natarajan. "Review of biodiesel composition, properties, and specifications." Renewable and sustainable energy reviews 16, no. 1 (2012): 143169.

15. Encinar, Jose M., Juan F. Gonzalez, and Antonio Rodríguez-Reinares. "Biodiesel from used frying oil. Variables affecting the yields and characteristics of the biodiesel." Industrial \& Engineering Chemistry Research 44, no. 15 (2005): 5491-5499.

16. Demirbas, Ayhan, and M. Fatih Demirbas. "Importance of algae oil as a source of biodiesel." Energy conversion and management 52, no. 1 (2011): 163-170.

17. Issariyakul, Titipong, and Ajay K. Dalai. "Biodiesel from vegetable oils." Renewable and Sustainable Energy Reviews 31 (2014): 446-471.

18. Pentaris, F. P., J. Stonham, and J. P. Makris. "A cost effective wireless structural health monitoring network for buildings in earthquake zones." Smart materials and structures 23, no. 10 (2014): 105010.

19. Huang, Daming, Haining Zhou, and Lin Lin. "Biodiesel: an alternative to conventional fuel." Energy Procedia 16 (2012): 1874-1885.

20. Karaosmanoğlu, Filiz, K. Barış Ciğızoğlu, Melek Tüter, and Serap Ertekin. "Investigation of the refining step of biodiesel production." Energy \& Fuels 10, no. 4 (1996): 890-895.

21. Christopher, Lew P., Hemanathan Kumar, and Vasudeo P. Zambare. "Enzymatic biodiesel: challenges and opportunities." Applied Energy 119 (2014): 497-520. 
22. Knothe, Gerhard. "Biodiesel: current trends and properties." Topics in catalysis 53, no. 11 (2010): 714-720.

23. Silitonga, A. S., T. M. I. Mahlia, Hwai Chyuan Ong, T. M. I. Riayatsyah, F. Kusumo, Husin Ibrahim, S. Dharma, and D. Gumilang. "A comparative study of biodiesel production methods for Reutealis trisperma biodiesel." Energy Sources, Part A: Recovery, Utilization, and Environmental Effects 39, no. 20 (2017): 20062014.

24. Demirbas, Ayhan. "Importance of biodiesel as transportation fuel." Energy policy 35, no. 9 (2007): 4661-4670.

25. Jakeria, M. R., M. A. Fazal, and A. S. M. A. Haseeb. "Influence of different factors on the stability of biodiesel: A review." Renewable and Sustainable Energy Reviews 30 (2014): 154-163.

26. Aransiola, Elizabeth Funmilayo, Tunde Victor Ojumu, O. O. Oyekola, T. F. Madzimbamuto, and D. I. O. IkhuOmoregbe. "A review of current technology for biodiesel production: State of the art." Biomass and bioenergy 61 (2014): 276-297.

27. Lim, Steven, and Lee Keat Teong. "Recent trends, opportunities and challenges of biodiesel in Malaysia: an overview." Renewable and Sustainable Energy Reviews 14, no. 3 (2010): 938-954.

28. Atadashi, I. M., M. K. Aroua, and A. Abdul Aziz. "Biodiesel separation and purification: a review." Renewable Energy 36, no. 2 (2011): 437-443.

29. Saxena, Parag, Sayali Jawale, and Milind H. Joshipura. "A review on prediction of properties of biodiesel and blends of biodiesel." Procedia Engineering 51 (2013): 395-402.

30. Huang, Daming, Haining Zhou, and Lin Lin. "Biodiesel: an alternative to conventional fuel." Energy Procedia 16 (2012): 1874-1885.

31. Lotero, Edgar, Yijun Liu, Dora E. Lopez, Kaewta Suwannakarn, David A. Bruce, and James G. Goodwin. "Synthesis of biodiesel via acid catalysis." Industrial \& engineering chemistry research 44, no. 14 (2005): 53535363.

32. Janaun, Jidon, and Naoko Ellis. "Perspectives on biodiesel as a sustainable fuel." Renewable and Sustainable Energy Reviews 14, no. 4 (2010): 1312-1320.

33. Lim, Steven, and Lee Keat Teong. "Recent trends, opportunities and challenges of biodiesel in Malaysia: an overview." Renewable and Sustainable Energy Reviews 14, no. 3 (2010): 938-954.

34. Kalam, M. A., and H. H. Masjuki. "Biodiesel from palmoil—an analysis of its properties and potential." Biomass and Bioenergy 23, no. 6 (2002): 471-479.

35. Casas, Abraham, José Ramón Ruiz , María Jesús Ramos , and Angel Pérez. "Effects of triacetin on biodiesel quality." Energy \& Fuels 24, no. 8 (2010): 4481-4489.

36. Dr. Amol Lokhande, Dr. C. Venkateswaran, Dr. M. Ramachandran, S. Chinnasami, T. Vennila, A Review on Various Implications on Re engineering in Manufacturing, REST Journal on Emerging trends in Modelling and Manufacturing Vol: 7(3), 2021,70-75.

37. Dr. Amol Lokhande, Dr. C. Venkateswaran, Dr. M. Ramachandran, C. Vidhya, R. Kurinjimalar, A Study on Various Implications on Reusing in Manufacturing, REST Journal on Emerging trends in Modelling and Manufacturing 7(2) 2021, 63-69

38. Gadde Mehar Chaitanya, M.P.Jenarthanan, C. Sathiyaraj, A Review on Glass fibre Reinforced Composites with Different Matrix, REST Journal on Emerging trends in Modelling and Manufacturing 7(1) 2021, 18-24.

39. Allahkarami, Zeynab, Ahmad Reza Sayadi, and Amol Lanke. "Reliability analysis of motor system of dump truck for maintenance management." In Current trends in reliability, availability, maintainability and safety, pp. 681688. Springer, Cham, 2016.

40. Lanke, Amol Arun, Seyed Hadi Hoseinie, and Behzad Ghodrati. "Mine production index (MPI)-extension of OEE for bottleneck detection in mining." International Journal of Mining Science and Technology 26, no. 5 (2016): 753-760.

41. Lanke, Amol, Hadi Hoseinie, and Behzad Ghodrati. "Mine production index (MPI): new method to evaluate effectiveness of mining machinery." Int. J. Environ. Chem. Ecol. Geol. Geophys. Eng 8 (2014): 714-718.

42. Ramachandran, M., Sahas Bansal, and Pramod Raichurkar. "Experimental study of bamboo using banana and linen fibre reinforced polymeric composites." Perspectives in Science 8 (2016): 313-316.

43. Raichurkar, Pramod, and M. Ramachandran. "Recent trends and developments in textile industry in India." International Journal on Textile Engineering \& Processes 1, no. 4 (2015): 47-50.

44. Chidambaram, P. K., and R. Ramakrishanan. "Manufacturing, testing of polymer nanocomposite and analysis of tennis racket frame." International Journal of Engineering and Technology Innovation 4, no. 1 (2014): 59.

45. Chidambaram, P. K., and R. Ramakrishanan Impact. "String Tension and Vibration Analysis of Nancomposite Based Tennis Racket Frame." Scholars Journal of Engineering and Technology (2014): 206-211.

46. Chidambaram, P. K., K. Thamilarasan, J. Barath Kumar, and L. Auxcilia Mary. "A review on turbines in power production using wind and hydro energy." Materials Today: Proceedings (2021).

47. Jayapriya, J., D. Muruganandam, M. Shantharaj, S. Thayumanavan, S. Suraj, and P. K. Chidabaram. "Design and analysis of glass fiber reinforced composites." Materials Today: Proceedings 26 (2020): 2491-2494.

48. Chidambaram, P. K. "Synthesis, Testing of Polymer Carbon Nanocomposite and Structural Analysis of Tennis Racket Frame." International Journal of Engineering Sciences \& Research Technology 2, no. 10 (2013). 
49. Chidambaram, P. K., and R. Ramakrishnan. "Mechanical properties and Morphological analysis of nylon6, 6/cloisite@ 20A Nanocomposite." National Journal on Advances in Building Sciences and Mechanics 3 (2012): 813.

50. Rajaperumal, C. Vengatesha, P. K. Chidambaram, M. Arputha Bibiana, and G. Arun. "Development of Dual purpose manual weeder." Materials Today: Proceedings (2021).

51. Thamilarasan, K., P. K. Chidambaram, A. Ponshanmugakumar, and V. Bharani. "Design and Automation of degreasing of oil from strained materials." Materials Today: Proceedings (2021).

52. Srividhya, K., P. K. Chidambaram, A. Sivasakthi, and P. Dharanidharan. "Pre concentration and analysis of trace quantities of heavy metals using coirpith." Materials Today: Proceedings (2021).

53. Chidambaram, P. K., S. JohnDaniel, and M. Ganesh Kumar. "Morphological Analysis of the Nylon6, 6 Matrix based Clay and Carbon Nano composites." Materials Today: Proceedings 16 (2019): 1344-1349. 